\title{
Methods of deconditioning persisting avoidance: Drugs as adjuncts to response prevention
}

\author{
JONAS TAUB, PAMELA TAYLOR, MARTIN SMITH, KIM KELLEY, \\ BRUCE BECKER, and LARRY REID \\ Bradley University, Peoria, Illinois 61606
}

\begin{abstract}
Rats were trained, across 3 daily sessions, to avoid intense footshock in an automated one-way avoidance box. Subsequent to training and termination of footshock, groups of rats received different treatments, and all were tested for persistence of avoidance 3 days later. One group's treatment was only handling, a no-treatment group. All other groups were given response prevention, i.e., $10 \mathrm{~min}$ on the previously shocking grid without the opportunity to avoid. Groups of rats experienced response prevention under the influence of saline or doses of drugs: meprobamate, meprobamate in conjunction with atropine, atropine alone, atropine methyl nitrate, physostigmine, ethanol, morphine sulfate, amphetamine, chlordiazepoxide, and chlorpromazine. Only atropine led to reliably less persisting avoidance than response prevention controls, whereas doses of chlordiazepoxide led to more persisting avoidance. These data provide little support for the idea that widely used "psychotropic" drugs are effective in aiding the reduction of anxiety-fear-avoidance when postdrug behavior is the criterion for a drug's effectiveness.
\end{abstract}

Breger and McGaugh (1965) criticized the behavioral therapy movement because it was not well grounded in laboratory science. Baum (1970a) was among the first to systematically test methods for deconditioning persisting avoidance. Using rats and an automated one-way avoidance apparatus, Baum (1965, 1970a) established avoidance, terminated the footshock used to establish the avoidance, and then observed the persistence of avoidance beyond termination of footshock. Between termination of footshock and testing for persistence of avoidance, various treatments were programmed. The paradigm of Baum allowed features of the various behavioral therapies to be compared (Baum, 1970a; Voss, Metja, \& Reid, 1974).

Among the examined procedures is response prevention (RP). RP in the automated one-way avoidance apparatus usually involves trapping the rat on the previously dangerous grid by removal of the ledge that had been made available for avoidance. The relationship between duration of $R P$ and amount of persisting avoidance has been studied (Baum, 1966). With given parameters of training, brief RP may increase persisting avoidance, moderately long RP decreases persisting avoidance, and prolonged RP eliminates persisting avoidance (Metja, Reid, Coon, Paxton, Prado-Alcala, Christy, Ganey \& Miller, 1974). RP is a procedure that forces "reality testing"' (Baum, 1970a) and is analogous to

This research was supported by Grant DA01049 from the National Institute of Drug Abuse, DHEW, and by Bradley University's Board of Research. We thank Professor Harold Dowell for his assistance. many procedures of "psychotherapy" in which the client is coerced into facing threatening circumstances that, in reality, are not dangerous.

The most popular therapy for hyperanxiety, irrational fear, and persisting avoidance among human clients is the prescription of psychotropic agents. Idealized treatment calls for some form of psychotherapy or counseling in addition to drugs. The rationale for using drugs involves the drugs' immediate effects in calming the agitated client and the idea that once a client experiences, in or out of psychotherapy, the anxiety-eliciting circumstances in the drugged state (i.e., "tranquilized") such an experience will lead to extinction of "irrational" anxiety-fear-avoidance and a remediation of the client's problems (May, 1971). Miller (1961) was among the first to demonstrate that extinction training under the influence of a psychotropic drug might not transfer to the nondrugged state. Nevertheless, drugs are used extensively. Because some drugs do not allow desirable transfer of training does not mean, of course, that all calming drugs have that liability. The paradigm developed by Baum for testing behavioral procedures for their efficiency in deconditioning persisting avoidance seems to be a reasonable paradigm for testing a drug's effectiveness.

Our initial testing of psychotropic agents as adjuncts to RP (Christy \& Reid, 1975; Cooper, Coon, Mejta, \& Reid, 1974) confirmed the results of others (e.g., Kamano, 1972; Miller, 1961), indicating that some drugs used as adjuncts to RP either reduced the usual effectiveness of RP or led to heightened persisting avoidance. Chlorpromazine, chlordiaze- 
poxide, and sodium amytal, at some doses, calmed the rat during RP but subsequently led to more persisting avoidance than would have been expected had the rat received no RP. Of the agents tested initially, only a low dose of amphetamine $(2 \mathrm{mg} / \mathrm{kg})$ seemed to be an efficient adjunct to RP. From one point of view, these results were very discouraging because it seemed that if the conclusions derivable from our studies with rats were applicable to the human clinical situation, then the widespread prescription of tranquilizing agents have had either no therapeutic effects or dangerous effects.

\section{METHOD}

\section{Subjects}

The subjects were 406 adult (194 to $460 \mathrm{~g}$ ) male, experimentally naive, Sprague-Dawley rats. Because preexperimental housing affects amount of persisting avoidance (Sautter \& Reid, 1973), preexperimental housing was standardized. Upon arrival at the laboratory, the rats were housed in large colony cages. Two days prior to first training session, a rat was housed in an individual cage and lived in that cage throughout the balance of the procedure. Food and water were always available.

\section{Apparatus \\ An automated one-way avoidance apparatus similar to the one described by Baum (1965) was used. It was a clear Plexiglas box $(30 \times 27.5 \times 38 \mathrm{~cm})$ fitted with an electrifiable grid floor and a retractable ledge that moved through one wall of the chamber. The ledge was $27.5 \mathrm{~cm}$ wide and, when not retracted, extended $6 \mathrm{~cm}$ into the box, $14 \mathrm{~cm}$ above grid floor. Shock intensity was always $1.3 \mathrm{~mA}$ and was generated by a Grason- Stadler shock source and scrambler. The rat's presence on the ledge was detected by a system of photoelectrically activated relays.}

\section{Procedure}

All rats were trained with a standard procedure. Without habituation to the apparatus, a rat was placed on the grid. After $10 \mathrm{sec}$, shock began and continued until the rat escaped to the ledge. The subject was allowed to remain on the ledge for $30 \mathrm{sec}$, after which the ledge retracted dropping the rat back to the grid. As soon as the ledge was completely retracted, it returned to begin the next trial. On the next and all subsequent trials, if a rat climbed to the ledge within $10 \mathrm{sec}$, it avoided shock, otherwise it was shocked until it escaped to the ledge.

One training session was 50 trials. A session ended with the rat on the ledge, from which it was removed and returned to its home cage. Each rat received one session a day for 3 consecutive days, a total of 150 trials. With the end of the 150th trial, footshock was terminated and not reinstated.

With the end of training, different treatment procedures were given to randomly selected groups of rats. After the 150th trial, the rat was picked up from the ledge and injected (intraperitoneally except in tests with morphine, which was injected subcutaneously) with either a drug or a placebo (the respective carrier for a drug). The rat was then placed in its home cage for a specified period (30 min, except following morphine injections) to allow the drug to take effect. The subject was returned to the room of the apparatus to receive either RP or "no treatment." During RP, the subject was on the grid with the ledge retracted and, of course, the shock source disconnected. All RP lasted $10 \mathrm{~min}$. During "no treatment," a rat was placed in a pail next to the apparatus for $10 \mathrm{~min}$. Following these procedures, the rat was returned to its home cage. The 10 -min RP period was chosen because pilot data had indicated that it was of sufficient dura- tion to reduce persisting avoidance but not eliminate it. Consequently, a drug could reduce or enhance effects of RP.

In addition to subjects of no treatment and of RP with placebo, there were rats that got the following drugs and doses and RP: (a) meprobamate in doses of $5,20,35,70$ and $100 \mathrm{mg} / \mathrm{kg}$ given to $10,10,18,8$, and 8 subjects, respectively; (b) meprobamate in conjunction with $9 \mathrm{mg} / \mathrm{kg}$ of atropine in doses of 5,20 , and $35 \mathrm{mg} / \mathrm{kg}$ given to 10 subjects a dose; (c) atropine in doses of 3,6 , and $9 \mathrm{mg} / \mathrm{kg}$ given to 8,8 , and 18 subjects, respectively; (d) atropine methyl nitrate, $18 \mathrm{mg} / \mathrm{kg}$, given to 10 subjects; (e) physostigmine in doses of $.2, .4$, and $.6 \mathrm{mg} / \mathrm{kg}$ given to 8,8 , and 7 subjects, respectively; (f) ethanol, $500 \mathrm{mg} / \mathrm{kg}$, to 24 subjects; (g) morphine sulfate, $10 \mathrm{mg} / \mathrm{kg}$, to 20 subjects; (h) amphetamine in doses of $2,4,10$, and $15 \mathrm{mg} / \mathrm{kg}$ to $11,11,14$, and 10 subjects, respectively; (i) chlordiazepoxide in doses of 5,10 , and $20 \mathrm{mg} / \mathrm{kg}$ to 9,11 , and 9 subjects, respectively; and (j)chlorpromazine in doses of 2 and $5 \mathrm{mg} / \mathrm{kg}$ given to 9 and 10 subjects, respectively. Because the procedure of Christy and Reid (1975) was nearly identical to the present one, except for the intervention 3 min into testing to disrupt freezing (to be described below), their results with sodium amytal are presented and discussed in relation to the present results. They tested sodium amytal in two doses 10 and $20 \mathrm{mg} / \mathrm{kg}, \mathrm{n}=7$ a dose.

All rats were tested for perseveration of responding $72 \mathrm{~h}$ after their treatments. Testing began by placing a rat on the ledge. The ledge retracted $30 \mathrm{sec}$ later, beginning trials the same as training trials except that a rat never received footshock. Testing continued until the subject remained on the grid for a period of 5 consecutive minutes or until it accumulated 335 trials (for some groups, the rats were allowed to respond beyond 335 trials, but to make groups comparable all analyses used the 335-trial limit).

After the first $3 \mathrm{~min}$ of testing had elapsed, regardless of whether the subject was on the ledge or on the grid, it was picked up, handled briefly in a standard way, and returned to the ledge. In pilot work during testing for persisting avoidance, it was found that some subjects tended to freeze on the grid after initial retraction of the ledge and to remain in that position to meet deconditioning criterion. If the subject was then placed back on the ledge and testing begun again, it would respond persistently. This suggested that the avoidance response had not really been deconditioned and pointed to the need to devise a more effective testing procedure. The brief handling of all rats after 3 min had elapsed was used because it could be used uniformly before any of the subjects could have met criteria and because it seemed effective in pilot work. The procedure interrupted most freezing behavior without interfering with those rats that were responding without freezing.

Since various drug groups were tested at separate times, usually a group of subjects of no treatment and always a group of subjects of RP with placebo were tested concurrently with subjects getting a particular drug. Consequently, the number of rats of no treatment and of RP with placebo increased with each succeeding test, eventually yielding a total of 52 subjects of no treatment and 65 subjects of RP with placebos. In general, the subgroups of subjects of no treatment and of RP with placebo performed similarly during tests of persisting avoidance. ANOVA of trials to criteria among subgroups of no treatment yielded an $F(6,45)=1.36, p>.25$. An ANOVA of trials to criteria among subgroups of $R P$ with placebo yielded an $F(7,57)=.27, p>.25$. From these analyses, we presume that time of testing and slight variations in training were not variables of consequence. We, therefore, combined the various subgroups of each treatment and used the total distributions of each group as the index of performance of rats of no treatment and of RP with placebo. Also, when a particular dose of a drug was tested with different subgroups, the subgroups were combined for this presentation of results.

In our previous studies (e.g., Hunsicker, Nelson, \& Reid, 1973), high levels of concordance were found between posttreatment measures, i.e., trials to criteria, "avoidance responses", 
to criteria (jumps to the ledge within $10 \mathrm{sec}$ ), "escapes" to criteria (jumps to the ledge after $10 \mathrm{sec}$ ), and latency of the first response. Consequently, we only measured trials to criteria and assumed that trials reflected other potential measures of persisting avoidance.

A special procedure preceded the testing of rats that got ethanol as the adjunct to RP. One-half of them (12) were given a flavored ethanol solution across a 30 -day period as their only source of fluid. Under these circumstances, the rats took about $9 \mathrm{~g} / \mathrm{kg} /$ day of ethanol. The other half took, for a comparable $\mathbf{3 0}$ days, only the flavored solution. This forced ethanol consumption was done to afford some of the rats experience with ethanol prior to its use as an adjunct to RP.

Morphine, in the dose we used, produces behavioral depression at $1 \mathrm{~h}$ after dosing and considerably less behavioral depression at $4 \mathrm{~h}$ after dosing. At both of these times after dosing, there is probably a positive affective state engendered (Rossi \& Reid, 1976). Rats were treated at both of these times after subcutaneous injections. All other procedures with morphine were the same as with other drugs.

\section{RESULTS}

This training procedure leads to efficient avoidance among rats. The subjects usually took a prolonged period of shock with the first trial (mean = $19.2 \mathrm{sec}$ ) and then took little shock subsequently (mean seconds of shock on all trials except the first one $=9.3 \mathrm{sec}$ on the $1 \mathrm{st}$ day of training). Mean trials of shock during the first 50 trials, including first trial, $=5.3$. Usually on the 2 nd and 3rd training days, the rats avoided on nearly all trials. When they did not avoid, it was usually on the first trial of a day (mean seconds of shock for 2 nd and 3 rd days $=2.3$ and $1.1 \mathrm{sec}$, respectively; mean trials of shock $=3.3$ and 1.4 , respectively).

All measures of training and trials to criteria were used to develop a matrix of correlations. The only measures that substantially correlated with one another were those of training that measured similar behavior, e.g., the correlation between seconds of shock of third session and number of shocks of the third session $=.75$. No measure of training, including totals across the three training sessions, correlated reliably with trials to criteria following treatment, e.g., the highest correlation of any pretreatment measure with posttreatment trials to criteria was -.12 between number of trials of shock of first training session and trials to criteria, and all others were less than .10. These correlations suggest that partialling out variability attributable to differences in pretraining performance would not significantly modify conclusions that are derived from merely analyzing trials to criteria.

Outcome data are summarized in Figure 1. The two data points on the left of Figure 1 and the dashed lines extending from those points represent the means of persisting avoidance of the two control groups. The probability values for assessing the reliability of differences from the two control groups were derived from Student $t$ tests (two-tailed standards) without taking into account the problems associated with concluding reliable differences from multiple $\mathrm{t}$ tests.

The rats of the control group of no treatment took a mean of 170.5 trials to reach deconditioning criteria with a standard deviation of 122.5 and with median of 154 and limits of interquartile range of 51 and 321.5 trials. The rats of the control group of RP with placebo took a mean of 97.6 trials with a standard deviation of 106.3 and with a median of 52 and an interquartile range of 19.8 to 140.2 trials. The large variability in the two control groups is characteristic of this procedure, and nearly all groups of a particular dose show similar variability. A Student-t comparing the two control groups yielded a $\mathrm{t}(115)=3.4, \mathrm{p}<.01$.

Like rats of RP with placebo, some groups of subjects getting a dose of a drug also persisted in avoidance reliably less than rats of no treatment. Among those groups responding less than subjects of no treatment were those of: (a) a single dose of meprobamate, (b) doses of meprobamate plus atropine, (c) ethanol in ethanol-naive rats, (d) the two groups of morphine, (e) two doses of amphetamine, and (f) one dose of amytal. None of these groups, however, responded reliably less than the subjects of RP with placebo. Furthermore, none of these groups responded reliably less than the RP controls tested at the same time. Therefore, the conclusion is reached that these agents do not reliably modify postdrug performance any more than RP without drug. Or, stated another way, these agents produce inconsequential effects with respect to our tests.

A number of other groups of subjects getting doses of drugs did not differ reliably from either the RP with placebo or the no-treatment controls (those groups are represented by black dots in Figure 1). In general, their average performance fell within the overlap in frequency distributions of the two control groups. To summarize, most of the agents and doses that were tested produced no reliable change in persisting avoidance.

Interestingly, rats of two doses of atropine responded less than the RP controls. All doses of physostigmine led to greater, although not reliably greater, performance than RP with placebo. Furthermore, the agent atropine methyl nitrate, which does not apparently cross the blood-brain barrier, did not lead to reduced responding as did doses of atropine.

Another set of results of some interest are those of doses of chlordiazepoxide. The $20-\mathrm{mg} / \mathrm{kg}$ dose led to reliably more persisting avoidance than RP with placebo. The other two doses produced, on the average, greater persisting avoidance than RP with placebo.

If this collection of results is analyzed using medians as measures of central tendency and distribution-free statistics, the same pattern of results 


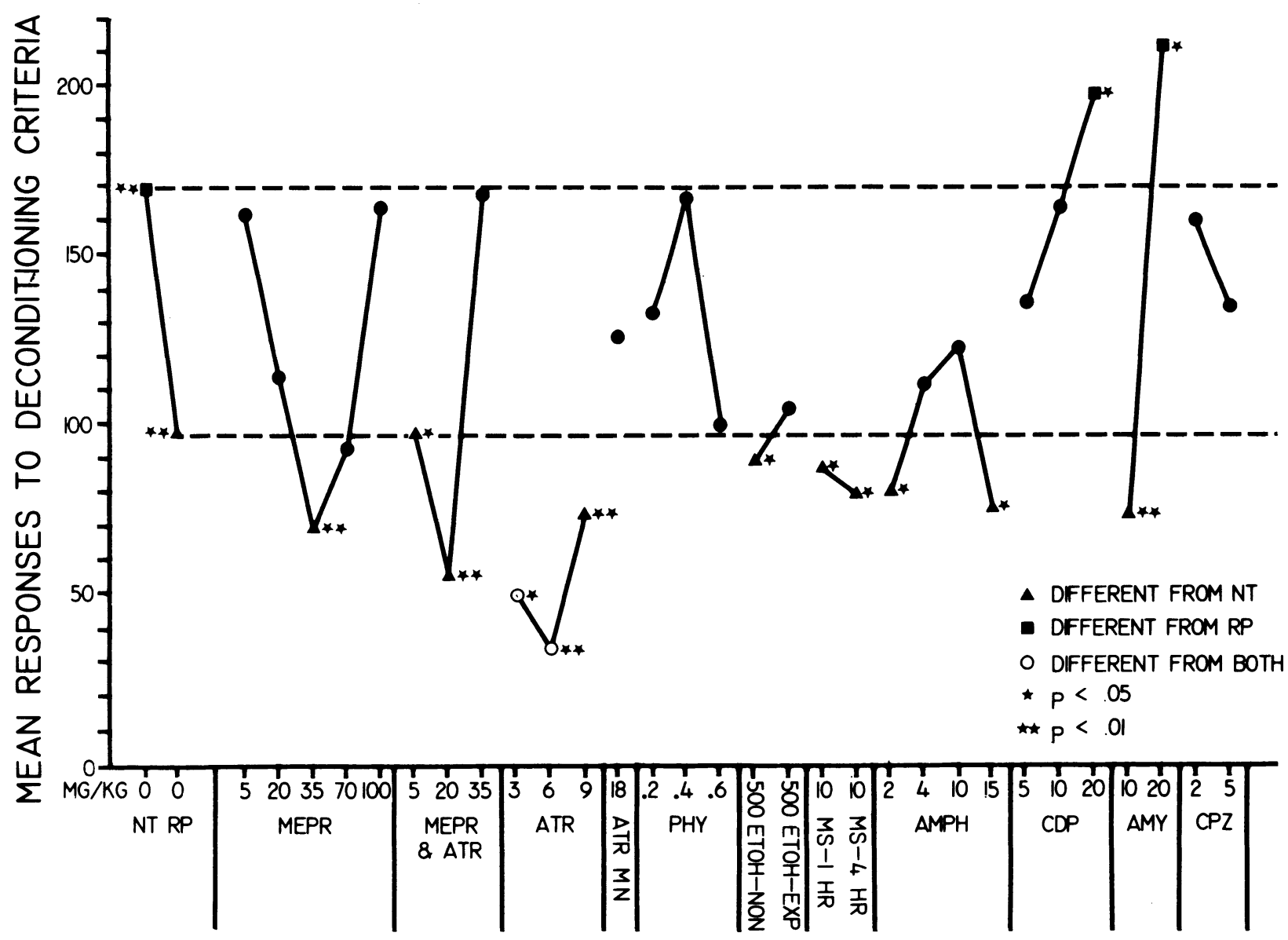

TREATMENTS

Figure 1. Mean trials to criteria for each group, a measure of persisting avoidance. Abbreviations: NT = no treatment, i.e., no response prevention; $\mathbf{R P}=10 \mathrm{~min}$ of response prevention under the influence of placebos; $M E P R=$ meprobamate; $A T R=$ atropine; PHY = physostigmine; ETOH = ethanol in rats experienced with ethanol and nonexperienced; MS = morphine sulfate 1 and $4 \mathrm{~h}$ after administration; AMPH = amphetamine; $\mathbf{C D P}=$ chlordiazepoxide; $\mathrm{AMY}=$ sodium amytal; $\mathrm{CPZ}=$ chlorpromazine. All rats that were administered doses of drugs were given $10 \mathrm{~min}$ of $\mathrm{RP}$ under the influence of the doses.

as presented in Figure 1 emerges. If you take the percentage of subjects responding less than 25 or 100 responses to criteria and analyze the results from that perspective, the same conclusions are derived as one might draw from the summary presented in Figure 1. Also, transforming the scores (e.g., square root transformations) will not change the conclusions that can be drawn.

\section{DISCUSSION}

In other studies (Christy \& Reid, 1975; Cooper et al., 1974), it was demonstrated that small doses of amphetamine were efficient adjuncts to RP. This study failed to demonstrate that amphetamine dosing led to less persisting avoidance. The procedures of the other studies were very similar to those reported here except for the procedure to interfere with freezing at the beginning of testing. Small doses of amphetamine may lead to some increased movement, which in turn might aid the processes of RP (Hunsicker et al., 1973; Liederhandler \& Baum, 1970), but evidently the beneficial effects of amphetamine are relatively dose specific and are limited to rather special testing circumstances. Because freezing is so typical of rats, it is presumed that any beneficial effects of low doses of amphetamine are species specific.

Aside from the results with amphetamine, these results are congruent with others. It has been shown that ethanol, chlorpromazine, and chlordiazepoxide are not efficient adjuncts to RP (Baum, 1969; 1973; Cooper et al., 1974; Kamano, 1972).

Ethanol as an adjunct to RP either does not reliably modify or enhances persisting avoidance (Baum, 1969, 1970b). Furthermore, it appears that ethanol has these effects (no effect or enhancement of persisting avoidance) in rats experienced with ethanol (Amit, Ziskind, \& Baum, 1973; this paper).

Chlorpromazine, chlordiazepoxide, sodium 
amytal, and meprobamate are all agents that have been shown to reduce fear or to interfere with the expression of behavior that usually follows application of an aversive stimulus. Yet none of these agents, as well as ethanol and morphine, which can also reduce fear and shock-motivated behavior, reduce persisting avoidance when used as adjuncts to RP. This lack of result with drugs is in marked contrast to application of positive intracranial stimulation and to prolonged RP (Baum, 1970a; Becker, Magnuson, \& Reid, 1977; Gordon \& Baum, 1971; Reid, 1973; Voss et al., 1974).

In the human clinic, drugs have been used successfully as adjuncts to systematic desensitization (Brady, 1966; Friedman, 1966; Kraft, 1967), but the agents used have been short-acting barbiturates. As Cooper et al. (1974) suggested, it appears that drugs blocking, or producing prolonged blunting of, the expression of fear do not provide the circumstances for the fear to be reconditioned (Wolpe's, 1973, term) by a counter-conditioner or to be extinguished. It makes little practical difference exactly what mechanism is responsible for the lack of effect (Cooper et al., 1974). It may be labeled an example of state-specific learning, lack of transfer, or lack of emotional learning, but regardless of the specific mechanism or label, fear-reducing drugs are not efficient adjuncts to RP.

Our data suggest that small and moderate doses are, in general, more efficient as adjuncts to RP (e.g., sodium amytal and chlordiazepoxide). Also, small doses have less addiction potential (Jarvik, 1970). But more important, the data lead to the suggestion that heavy doses of some drugs (especially chlordiazepoxide and ethanol) have the ultimate effect of enhancing persisting avoidance (Baum, 1969; Kamano, 1972; this paper). Ethanol use, as well as tranquilizer use, might in the long run enhance anxiety-fear-avoidance rather than reduce it (Cappell \& Herman, 1972). This observation leads to the plausible hypothesis that high levels of anxiety seen with persistent heavy use of ethanol and of tranquilizers might be a symptom of the use of these agents, and not the putative potent antecedent for their use.

A criticism of our conclusions might rest on the proposition that our laboratory test is not an appropriate test for assessing the effectiveness of psychotropics to manage anxiety-fear-avoidance. The typical laboratory test for antianxiety drugs, probably because it is simple to do, is to see if an agent will reduce suppression of shock-induced hesitancy to drink when thirsty. Rats are made thirsty by deprivation and then shocked when they attempt to drink. Under these circumstances, rats are, to no one's surprise, hesitant to drink. An efficient psychopharmacological supposedly reduces rats' hesitancy to drink and allows them to take shock. An agent passing this typical test might be useful for promoting bravery in the face of real danger, or foolhardiness, but may or may not promote appropriate reconditioning. Much the same can be said for other putative laboratory tests assessing effectiveness of antianxiety agents. Our test is a test of an agent as an adjunct to RP, and as such, a test for whether or not the agent promotes reconditioning, which is the desirable result. We submit that our test is more appropriate than many others for assessing the potential therapeutic benefits of an agent in managing irrational anxiety-fear-avoidance, including the imprecise test of clinical experience (see below).

Jarvik (1970), in reviewing the scientific status of the use of psychotropic agents, stated that there is no rational basis for the widespread use of popular antianxiety agents. Furthermore, in a large computer-based study of drug assignment, it was found that, for clients not presenting symptoms of psychosis or alcoholism, "minor tranquilizers are prescribed for this group of patients in a virtually random and unpredictable manner or at least in a manner that cannot be effectively predicted by any combination of the 195 variables explored in this study" (Altman, Evenson, Sletten, \& Cho, 1974, p. 508). The only rationale seems to be the ease of prescription of the agents and the supposition that the individual profits from the experience accompanying bolder behavior in the drugged state. Tests of "anti-anxiety agents" as adjuncts to RP assess part of the rationale, and these tests have failed to show that these agents are desirable adjuncts to RP. Because drugs we have tested fail, in general, to meet a standard for effectiveness does not mean, of course, that other drugs will also fail to meet the standard.

Of the drugs tested, only atropine could be considered to have the desirable property of being an efficient adjunct to RP. Jarvik (1970, p. 180) said it has been known for years that the belladonna alkaloids have "tranquilizing" properties, and, of course, atropine is a belladonna alkaloid. A fault of our study, however, is that the likelihood of making a Type I error is greater than desirable. Unlike with other agents, there are no other known studies of atropine as an adjunct to RP to confirm our results, although there are a considerable number of studies of atropine and physostigmine on learning capabilities (e.g., Burešová, Bureš, Bohdanecký, \& Weiss, 1964; Whitehouse, 1966). The conclusion we draw, therefore, is that atropine may be an efficient adjunct to RP and that an effective adjunct to RP should surely not increase cerebral acytecholine. Also, this property of atropine and similar agents should be taken into account in studies of their effects on learning capabilities, particularly when shock-motivated behavior is being studied.

From the animal laboratory and from the experi- 
mental clinic, procedures have been developed for managing anxiety-fear-avoidance: the procedures of the behavior therapy movement. The behavioral therapies are bolstered by strong data and consistent rationale both from the animal laboratory (Baum, 1970a; Reid, 1973) and the experimental clinic (Franks \& Wilson, 1975; Wolpe, 1973). In contrast, the use of drugs to manage anxiety-fear-avoidance is at best weakly supported by data of the animal laboratory (this paper plus references cited) and has at best weak rationale underlying their use (Jarvik, 1970), and the procedures have important potentially deleterious side effects (Jarvik, 1970; Kellner, 1975). For these reasons, it would seem desirable to provide behavioral therapy for "neurotic" anxiety and not drug therapy.

\section{REFERENCES}

Altman, H., Evenson, R. C., Sletten, I. W., \& Cho, D. W. Computer prediction of psychotropic drug assignment in state mental facilities: Effect of eliminating alcoholics from the study sample. Diseases of the Nervous System, 1974, 35, 505-508.

AMit, Z., Ziskind, D., \& BAUM, M. Drug effects and avoidanceextinction in rats: A test of the drug-novelty hypothesis using ethanol. Animal Learning \& Behavior, 1973, 1, 41-43.

BAUM, M. An automated apparatus for the avoidance training of rats. Psychological Reports, 1965, 16, 1205-1211.

BAUM, M. Rapid extinction of an avoidance response following a period of response prevention in the avoidance apparatus. Psychological Reports, 1966, 18, 59-64.

BAUM, M. Paradoxical effect of alcohol on the resistance to extinction of an avoid ance response in rats. Journal of Comparative and Physiological Psychology, 1969, 69, 238-240.

BAUM, M. Extinction of avoidance responding through response prevention (flooding). Psychological Bulletin, 1970, 74, 276-284. (a)

BAUM, M. Effect of alcohol on the acquisition and resistance-toextinction of avoidance responses in rats. Psychological Reports, 1970, 26, 759-765. (b)

BAUM, M. Extinction of avoidance in rats: The effects of chlorpromazine and methyl-phenidate administered in conjunction with flooding response (prevention). Behavior Research and Therapy, 1973, 11, 165-169.

Becker, B., Magnuson, D., \& Reid, L. Methods of deconditioning persisting avoidance: Intracranial stimulation as a counterconditioner. Physiological Psychology, 1977, 5, 73-75.

BRADY, J. P. Brevital-relaxation treatment of frigidity. Behavior Research and Therapy, 1966, 4, 71-77.

BREGER, L., \& McGaUGH, J. L. Critique and reformulation of "learning-theory" approaches to psychotherapy and neurosis. Psychological Bulletin, 1965, 63, 338-358.

Burešová, D., Bureš, J., Bohdanecký, Z., \& Weiss, T. Effect of atropine on learning, extinction, retention and retrieval in rats. Psychopharmacologia (Berl.), 1964, 5, 255-263.

Cappell, H., \& Herman, C. P. Alcohol and tension reduction. Quarterly Journal of Studies on Alcohol, 1972, 33, 33-64.
Christy, D., \& Reid, L. Methods of deconditioning persisting avoidance: Amphetamine and amobarbital as adjuncts to response prevention. Bulletin of the Psychonomic Society, 1975, 5, 175-177.

Cooper, S., Coon, K., Mejta, C., \& Reid, L. Methods of deconditioning persisting avoidance: Amphetamine, chlorpromazine, and chlordiazepoxide as adjuncts to response prevention. Physiological Psychology, 1974, 2, 519-522.

Franks, C. M., \& Wison, G. Annual review of behavior therapy: Theory and practice. New York: Brunner/Mazeo, 1973.

Friedman, D. A new technique for the systematic desensitization of phobic symptons. Behavior Research and Therapy, 1966, 4, 139-140.

Gordon, A., \& BAUM, M. Increased efficacy of flooding (response prevention) in rats through positive intracranial stimulation. Journal of Comparative and Physiological Psychology, 1971, 75, 68-72.

Hunsicker, J. P., Nelson, T. C., \& Reid, L. D. Two kinds of intracranial stimulation as counterconditioners of persisting avoidance in rats. Physiological Psychology, 1973, 1, 227-230.

JARVIK, M. E. Drugs used in the treatment of psychiatric disorders. In L. S. Goodman \& A. Gilman (Eds.), The pharmacological basis of therapeutics. New York: MacMillan, 1970.

Liederhandler, I., \& BAUM, M. Mechanical facilitation of the action of response prevention (flooding) in rats. Behavioral Research \& Therapy, 1970, 8, 43-48.

Kamano, D. K. Using drugs to modify the effects of response prevention on avoidance extinction. Behavior Research and Therapy, 1972, 10, 367-370.

KELLNER, R. Unwanted effects of minor tranquilizers and hypnotics. Psychiatric Annals, 1975, 5, 459-463.

KRAFT, T. The use of methohexitone sodium in behavioral therapy. Behavior Research and Therapy, 1967, 5, 275.

MAY, P. R. A. Psychotherapy and ataraxic drugs. In A. E. Bergin \& S. L. Garfield (Eds.), Handbook of psychotherapy and behavior change. New York: Wiley, 1971.

Mejta, C., Reid, L., Coon, K., Paxton, R., Prado-Alcala, R., Christy, D., Ganey, C., \& Miller, R. Methods of deconditioning avoidance: II. JSAS Catalogue of Selected Documents in Psychology, 1974, 4, 119-120.

Miller, N. E. Some recent studies of conflict behavior and drugs. American Psychologist, 1961, 18, 12-24.

REID, L. D. Processes of fear reduction in systematic desensitization: An addendum to Wilson and Davison (1971). Psychological Bulletin, 1973, 79, 107-109.

Rossi, N., \& ReID, L. D. Affective states associated with morphine injections. Physiological Psychology, 1976, 4, 269-274.

SAUTtER, F. J., \& REID, L. D. Effects of prolonged training, differential housing, and response prevention on persisting avoidance in rats. Bulletin of the Psychonomic Society, 1973, 2, 239-241.

Voss, E., Mejta, C., \& ReID, L. Methods of deconditioning persisting avoidance: Response prevention and counterconditioning after extensive training. Bulletin of the Psychonomic Society, 1974, 3, 345-347.

Whitehouse, J. M. The effects of physostigmine on discrimination learning. Psychopharmacologia (Berl.), 1966, 9, 183-188.

WOLPE, J. The practice of behavior therapy. New York: Pergamon Press, 1973.

(Received for publication August 3, 1976; revision accepted December $15,1976$. 